\title{
IJPPR
}

Human Journals

Review Article

April 2020 Vol.:18, Issue:1

(c) All rights are reserved by Akshay R. Barkate et al.

\section{Methods of Pelletization Using Extrusion - Spheronization: A Review}

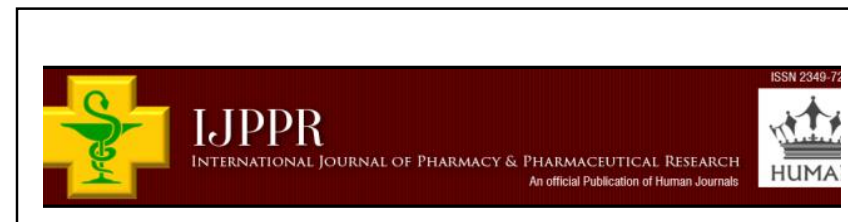

Akshay R. Barkate*, Sunil B. Bothara, Paresh R. Mahaparale, Priyanka S. Lohar, Somnath B.

\section{Tambade}

Department of Pharmaceutics, Government College of Pharmacy, Aurangabad, Maharashtra, India-431005.

Submission: 22 March 2020

Accepted: $\quad 30$ March 2020

Published: $\quad 30$ April 2020
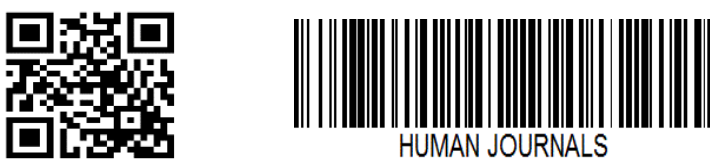

www.ijppr.humanjournals.com

DOI: 10.25166/ijppr.2020.v18i01.029
Keywords: Pellets, Spheronization, Extrusion, Pelletization techniques, Hot Melt Extrusion

\section{ABSTRACT}

Nowadays, multiple unit dosage forms (MUDF) are preferred as they offer many benefits over a single unit dosage form. The extrusion-spheronization technique is the most widely used technique for the production of MUDF. This article deals with multiple aspects and parts of the extrusion-spheronization techniques. The initial part deals with different steps in the manufacturing of pellets such as granulation, extrusion, spheronization, and drying while the final part deals with the parameters that govern the quality of pellets. Wherein formulation aspects like moisture content, granulating liquid, excipients and API, equipment aspects like a mixer, extruder, friction plate, and extrusion screen and process aspects like extrusion temperature, extrusion speed, spheronization time, spheronizer load, spheronization speed, and drying, etc. This review also summarizes the pallets characterization aspects like particle size distribution, surface area, and surface roughness, tensile strength, angle of repose, scanning electron microscopy, accelerated stability study properties, etc. 


\section{www.ijppr.humanjournals.com}

\section{INTRODUCTION:}

Nowadays, the interest in pellets that can be filled into the hard gelatin capsules or for making a tablet by compressing is increasing [1]. Pellets are the small free-flowing, spherical particulates, manufactured by the process of agglomeration of fine powder or granules [2]. The different technologies are available to make pellets, also known as micro-granules that are spherical in the shape of varying in diameter [3]. Currently, there has been a growing interest in the field of pelletization techniques to produce a large number of spherical pellets that can be incorporated into several dosages forms like capsules and/or tablets or can be administered as such by various routes. Pelletization techniques involve the size enlargement process of the core, the final core material agglomerates are spherical and ranging from0.5-2.0 $\mathrm{mm}$ in size then these are referred to as pellets. Dosage form made using pellets offer several benefits over other dosage forms like fast dissolution that results in rapid drug absorption, low gastric irritation because of fast dissolution that leads to lower time residence of drug and dose dumping, good flowability due to uniform size and shape, narrow particle size distribution, high tensile strength, a low surface to volume ratio, low friability and uniform packing characteristics of pellets [4]. This technology can be used for the formulation of controlled drug delivery [5] and sustained release formulations [6] to be administered via the oral route.

Microcrystalline cellulose of various grades is the most essential components in the extrusion -spheronization process [7], as they possess good water uptake capacity, water holding capacity, cohesiveness and it's plastic behavior when it can be wetted [8,9]. Some other hydrophilic gel-forming polymers like Pectin [10, 11], Chitosan [12, 13], K-Carrageenan [14], Alginate [15, 16], Hydroxypropyl methylcellulose (HPMC) [17] can also incorporated. Some water-insoluble polymers like Eudragit RL and Eudragit RS used as an alternative excipient for the preparation of pellets $[18,19]$.

\section{History of Pellets}

In the year 1949, the scientist's Smith Kline \& French developing the sustained-release pellet formulation and started the development of tiny drug pellets of various active constituent that could be loaded into the capsule [20]. The pellet formulation, their processing methods, and equipment were used faster, cheaper, and more efficient [21]. 


\section{www.ijppr.humanjournals.com}

\section{Application of Pellets [22, 23]}

Increasing dissolution and solubility rate of the poorly soluble drug, Mask the bitter taste of the drugs, Pellets can improve compressibility and flow-ability, the Targeted release of active medicament in the colon.

\section{Formation and Growth Mechanism of Pellets}

To enhance any pelletization procedure, it is important to comprehend the key instruments of the beginning and development of pallets. The nucleation, coalescence, layering, abrasion transfer, and size reduction are the main events that can lead to an increase in the size and growth of pellets [24]. Powder (API + appropriate polymer) is wetted with a suitable solvent system for the nucleation process. The collision between well-formed nuclei moieties forms a large size particle known as coalescence. The successive addition of materials on already formed nuclei is known as layering. Abrasion transfer is a process of transfer the materials from one particle to another particle without any preference in any direction. Well-formed particles may undergo size reduction due to the attrition mechanism [24, 25].

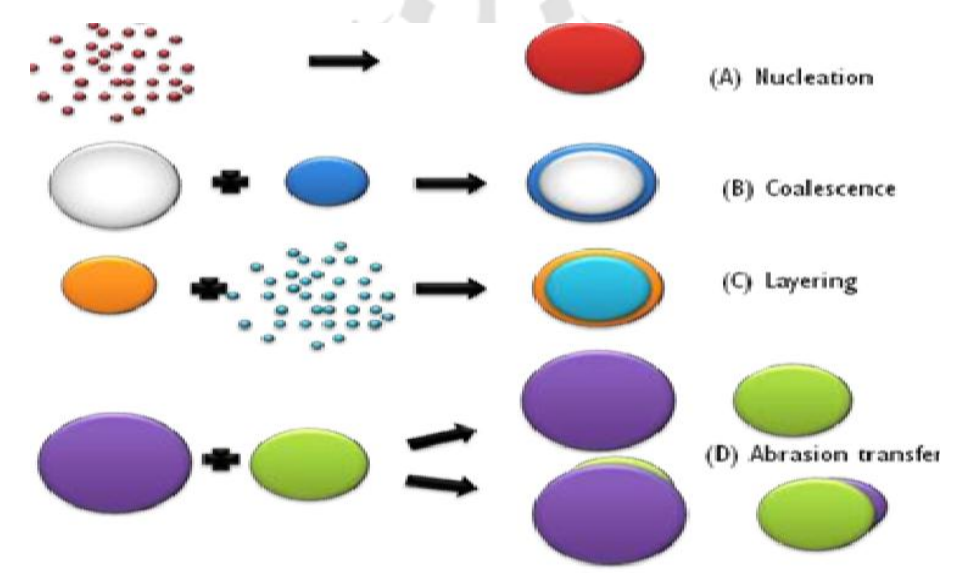

Figure No. 1: Mechanism of growth formation [26].

\section{Pelletization Techniques}

Several pelletization techniques are as follows.

The growth of pellets may depend upon the types of equipment and processes that have been selected, various pelletization techniques are as follows. 


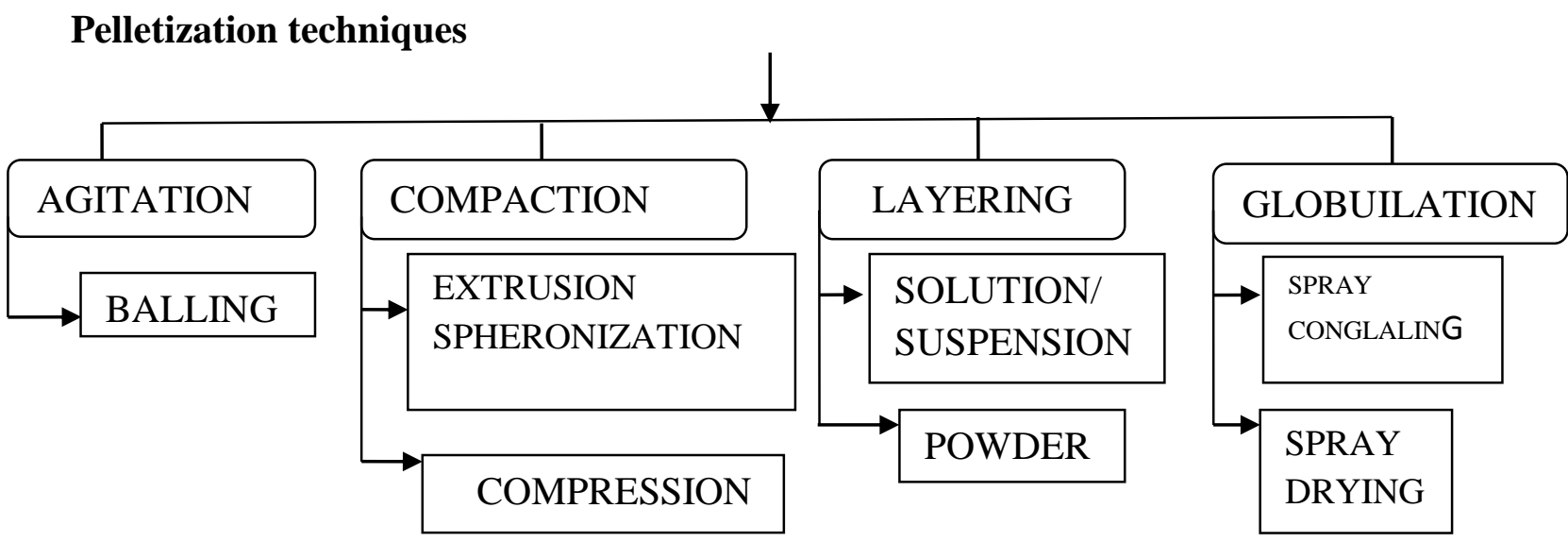

Figure No. 2: Pelletization Technique.

\section{Agitation}

When an appropriate quantity of liquid is added to finely divided particles that are continuously rolling or in tumbling motion, these particles are converted into spherical pellets. The liquid may be added before or during the agitation process. In the balling process, the equipments like discs, Pans, mixers, or drums can be used to produce pellets [20, 27].

\section{Compaction}

The pellets of different sizes and shapes are manufactured using mechanical force. In the compaction process, the drug particles are prepared by wet granulation or dry blending process. The next step is drying which results in the particles undergo elastic as well as plastic deformation. Firstly, the dry powder is mixed with binding liquid to form an agglomerated mixture which is placed in the extruder to form high-density extrudates (HDE). The spheronizer is used to convert HDE to the pellets of the desired size and shape $[28,29]$.

\section{Drug layering}

It involves the deposition of more than one layer of drug entities from the solution, dry powder, suspension, and binder on the core of the same material [30]. The moist core which rotates in a rotating disc or pan which picks up dry powder that adheres to each other and the capillary energy generated in the liquid phase results in the formation of nuclei. The additional binding liquid is sprayed until the desired pellet sizes are obtained. In a suspension or solution layering, the drug particle solutions is prepared in binding liquid or are suspended in the binding liquids, these are sprinkled on core followed by drying. The spreading capacity of liquids depends on 


\section{www.ijppr.humanjournals.com}

the wettability of the material, droplet dynamics, and droplet wetting characteristics of the materials. The scientist Kovacevic et al. carried out a comparison between the solutions layering, suspension layering, powder layering for the manufacturing of enteric-coated pellets, and mentioned that suspension layering is excellent than other layering techniques for drug loading [31, 32].

\section{Globalization}

The pellets of different sizes and shapes are generated by an atomized liquid containing drug and polymers. The atomized droplets are contacted with a hot gas stream and the evaporation of the liquid is initiated during the process of spray drying. The evaporation process involves the simultaneous heat and mass transfer. This depends upon several factors like humidity, temperature, and transport properties of air which is surrounded by droplets during the spray congealing process. Below the melting point of the vehicle, the atomized droplets are chilled. A most important requirement in this process is that the substances having a small melting point area or sharp melting point $[24,25]$.

\section{Freeze Pelletization}

It is the technique used for the manufacturing of pellets of required size and shape by introducing the droplets of immiscible molten solid carrier or matrix containing different types of additives like diluents, disintegrates, surfactants and releases modifiers with or without active pharmaceutical agent into inert liquid columns. The liquid droplets are initiated using nozzles, needles, or atomizer into the inlet of the liquid column, dropped from a certain height so that droplets remain intact as they fall into the liquid columns. Freeze pelletization technique can be scaled-up by increasing the nozzle numbers up to several hundred which are not only based upon the desired rate of production of pellets but also depends upon static or vibrated electrically. Depending upon the pellet sizes, different sizes of needles are used. The droplets are move either on the top or to the bottom of the column which depends upon their densities of every droplet concerning liquid in the column. The two apparatus are designed which are based upon the movement of molten solid droplets. In the former freeze pelletizer, the droplets are initiated at the top through the inlet and formed droplets are settled at the bottom of the column, the settling rate of droplets based upon the matrix droplet density which is more than liquid column density. In another, when the carrier droplets densities are less than the liquid in the column, these droplets can be solidified at the top or the bottom of the column. The column 


\section{www.ijppr.humanjournals.com}

made up of borosilicate glass with a 24-inch length which is divided into two portions. In the first portion with a temperature of $250^{\circ} \mathrm{C}$ to $1000^{\circ} \mathrm{C}$ which is a region where the droplets are introduced. Other is the cooling portion at which the liquids droplets are allowed to solidify and result in spherical pellets having a temperature in the range of $0^{\circ} \mathrm{c}$ to $-400^{\circ} \mathrm{c}$ maintained by using acetonitrile-dry ice or salt-ice as a cooling agent. The carrier which is used during the whole process should be solid at Room Temperature and having the melting point below $100^{\circ} \mathrm{C}$ to minimize the degradation of active pharmaceutical constitutes $[33,34]$.

\section{Hot Melt Extrusion (HME)}

Different dosage forms like granules, pellets, tablets, and implants, etc are manufactured by HME. This technique is widely and most commonly used firstly by BASF Pharmaceuticals. The hot-melt extrusion consists of compaction and conversion of powder blend into a product of uniform size and shape. The different types of Polymer are melted and these polymers are combined with other excipients and active pharmaceutical ingredients through a die or orifice that are placed under controlled temperature, pressure, and screw speed, etc to form products of different sizes and shapes. The hot-melt extrusion process occurred by following steps. The first step is Feeding of the extruder through a hopper, Mixing followed by grinding and kneading. The next step is the Flow-through die $[35,36]$.

The Hot melt extrusion having the following benefits over a wet mass extrusion process [37].

It is a continuous process that requires fewer processing stages. It does not involve the addition of water or other solvents. The absence of water or other solvents may prevent the degradation of many drugs. Various active constitutes having a bitter taste, so it helps to masks it.

Disadvantages of hot melt extrusion [38].

It required high energy input during the process, Heat-sensitive materials or active constituents can not be used during the process.

\section{Factors Affecting Pelletization Technique.}

Several factors can affect the quality and characteristics of pellets. 


\section{www.ijppr.humanjournals.com}

\section{Moisture content}

An appropriate amount of moisture (10-15\%) is required for spherical pellets. The high amount of moisture is present in the dump mass, which can lead to the agglomeration of pellets during the spheronization process [39]. A low amount of moisture content is present in dump mass, which can lead to the production of fines extrudates with large variation in the size distribution of pellets [25].

\section{Rheological properties [39]}

The Rheological parameter of the wet mass determines the flowability in the extrusion machine. The optimum rheological condition leads to get good flowability of extrudates to extrude the wet mass. Variation in rheological condition makes improper and non-uniform extrusion, can lead to the non-uniform pallets.

\section{Composition of Granulating Fluid [39]}

Other than water, alcohol, water/alcohol mixture, ethyl ether, dilute acetic acid or isopropyl alcohol is used as a granulating liquid. Lower limits of $5 \%$ of granulation liquid have to be water to produce good quality of pellets.

\section{Physical Properties of Starting Materials [25]}

The physical properties of all starting materials such as composition, types of filler, particle size, etc can affect the quality of pellets. The release rate of the drug from the pellets depends upon the swelling properties of all starting materials used for the preparation of pellets.

\section{Characterizations of Pellets}

The following tests are performed on pellets to evaluate their nature.

\section{Pellet size distribution}

The pellet size is a very important parameter because of various significant influences on the release kinetics of a drug from formulation [33]. Pellet size is determined by measuring the mean ferret diameter, mean geometric diameter and mean length along with the width of pellets. Particle size distribution should be narrow as possible to ensure that the minimum variation in different coating thicknesses and to facilitate the blending process. For measuring 


\section{www.ijppr.humanjournals.com}

the particle size distribution, the Sieve analysis using a sieve shaker is the most useful method. Another method used for direct determining the particle size distribution is optical microscopy and scanning electron microscope (SEM) is another method used to measure the diameter of pellets $[40,41]$.

\section{Surface Area and Surface Roughness}

The surface area is measured by using Air Permeametry method was determined firstly by the scientist Eriksson et al [42]. To determine the surface roughness, Laser Profilometry method is used which has the aperture angles $53^{\circ}$, laser spot size $1 \mu \mathrm{m}$ with a measuring area $200 \times 200$ $\mathrm{mm}$ and resolution 1000 points/mm in the X-Direction and 500 points/mm in a Y-Direction. The scanning speed of laser profilometry is 100 points per sec. The final result obtained is the surface roughness mean and standard deviation of five pellets [43].

\section{Density}

Bulk density and tap density of the pellets are used to determine the uniqueness of particle size distribution of the pellets [44]. The pellet density can be affected by changing the process or change the formulation and many other factors or processes like the capsule filling, coating as well as mixing. Automated tapper is used to measure the bulk density of the pellets. The extent of compactness of various substances indicates a true density which can be determined by Solvent Displacement Method, Air-Comparison Pycnometer Method, and Helium Pycnometer Method [45].

The bulk density is determined by the following formula.

$$
\text { Bulk density }=\frac{M}{V}
$$

Whereas

' $\mathrm{M}$ ' is the exact numbers of pellets are placed into a measuring cylinder and ' $\mathrm{V}$ ' is the volume occupied by the pellets without disturbing to measuring cylinder [46].

Tap density is determined by the following formula.

$$
\text { Tap density }=\frac{M}{V 0}
$$




\section{www.ijppr.humanjournals.com}

Whereas,

' $\mathrm{M}$ ' is the exact quantities of pallets in measuring cylinder and V0 is the final volume after tapping [47].

\section{Tensile strength}

The quality required to give the strained to the pellet is called elasticity. It very well may be controlled by utilizing elastic mechanical assembly with a $5 \mathrm{~kg}$ load cell; the pellets are stressed until it breaks. The heap is recorded and the elasticity is determined by applying the incentive for the disappointment load and the range of the pellets [48].

\section{Angle of Repose}

The flow properties of powders, granules, and pellets are determined by measuring the angle of repose. A fixed funnel method is used to measure the angle of repose. The pellets are poured in the funnel until the highest point of the heap just contacts the tip of the pipe of the funnel. The following formula is used to determine the angle of repose.

$$
\operatorname{Tan} \theta=\frac{\mathrm{h}}{\mathrm{r}}
$$

Whereas

$\theta$ is the angle of repose

$\mathrm{h}$ is the height of the cone,

$r$ is the radius of the cone base $[49,50]$.

\section{SEM Analysis}

A thin layer of gold is coated with the sample by Sputter Coater Unit and photographs are taken by scanning electron microscopy (SEM) which is operated at a 1000 Volt accelerated voltage [51].

\section{Accelerated stability studies}

Stability testing is a very important part of information development. It provides evidence that the quality of formulation varies with time under certain influences [52]. The different batches 
of the formulation are stored at different temperatures at $25^{\circ} \mathrm{c} / 60 \%$ Room Humidity, at $30^{\circ} \mathrm{C} / 65 \% \mathrm{RH}$ and at $40^{\circ} \mathrm{C} / 75 \% \mathrm{RH}$ for several months as per guidelines given by ICH. During the accelerated stability studies, various physicochemical aspects like appearance, percentage drug content, and release profile, etc are continuously monitored for 3 months or as per ICH guidelines [53].

\section{Current Product Portfolio [4, 54, 55, 56, 57]}

Pellets (drugs containing) used for Production of capsule and Tablet Dosage Forms.

Table No. 1: Delayed-release/ enteric coated pellets

\begin{tabular}{|l|l|}
\hline 1 & Pantoprazole \\
\hline 2 & Duloxetine Hydrochloride \\
\hline 3 & Dexlansoprazole \\
\hline 4 & Rabeprazole \\
\hline 5 & Aspirin \\
\hline 6 & Tamsulosin Hydrochloride \\
\hline 7 & Doxycycline Hyclate \\
\hline 8 & Omeprazole \\
\hline 9 & Lansoprazole \\
\hline 10 & Esomeprazole Magnesium \\
\hline 11 & Diclofenac Sodium \\
\hline 12. & Propranolol \\
\hline
\end{tabular}

Table No. 2: Controlled Release Extended-Release/Time Release/Sustained Release Pellets

\begin{tabular}{|l|l|}
\hline 1 & Venlafaxine $\mathrm{HCl}$ \\
\hline 2 & Diclofenac Sodium \\
\hline 3 & Diclofenac Potassium \\
\hline
\end{tabular}


www.ijppr.humanjournals.com

Table No. 3: Taste Masked Micro Pellets

\begin{tabular}{|l|l|}
\hline 1 & Ciprofloxacin Hydrochloride \\
\hline 2 & Azithromycin \\
\hline 3 & Clarithromycin \\
\hline
\end{tabular}

Table No. 4: Immediate Release Coated Pellets

\begin{tabular}{|l|l|}
\hline 1 & Itraconazole \\
\hline 2 & Flurbiprofen \\
\hline 3 & Folic Acid \\
\hline 4 & Domperidone \\
\hline
\end{tabular}

Table No. 5: Oral Cephalosporin's (API)

\begin{tabular}{|c|l|}
\hline 1 & Cefuroxime Axetil \\
\hline 2 & Cefadroxil \\
\hline 3 & Cephalexin \\
\hline 4 & Cefdinir \\
\hline 5 & Cefixime \\
\hline 6 & Cefpodoxime \\
\hline 7 & Cefaclor \\
\hline 8 & Cephradin \\
\hline
\end{tabular}

\section{CONCLUSION:}

Pelletization techniques enhance its scope in the pharmaceutical industries like tablets, capsules, etc. for the manufacturing of controlled, immediate as well as the sustained release formulation for better bioavailability of active constituent. The extrusion- spheronization technique is widely used in pharmaceutical Industries because of its fast working with its economic, simple designing and high efficacy of production of pellets of different sizes and shapes. Various characteristic tests mentioned here to evaluate its nature. 


\section{www.ijppr.humanjournals.com}

\section{REFERENCES:}

1. Dukić-Ott A, Thommes M, Remon JP, Kleinebudde P, Vervaet C. Production of Pellets via ExtrusionSpheronisation Without the Incorporation of Microcrystalline Cellulose: A Critical Review. Eur J Pharm Biopharm. 2009;71(1):38-46.

2. Chatlapalli R, Rohera BD. Physical Characterization of HPMC and HEC and Investigation of Their Use as Pelletization Aids. Int J Pharm. 1998;161(2):179-93.

3. Sirisha K. VR, Vijaya Sri K, Suresh K, Kamalakar Reddy G and Devanna N: A review of Pellets and Pelletization process - A Multiparticulate Drug Delivery System. Int J Pharm Sci Res 2013; 4(6); 2145-2158.

4. Ahir AA, Mali SS, Hajare AA, Bhagwat DA, Patrekar P V. Pelletization Technology: Methods and Applications - A Review. Res J Pharm Technol. 2015;8(2):131-8.

5. Issa MG, Pessole L, Takahashi AI, Filho NA, Ferraz HG. Physicochemical and Dissolution Profile Characterization of Pellets Containing Different Binders Obtained by the Extrusion-Spheronization Process. Brazilian J Pharm Sci. 2012;48(3):379-88.

6. Sunke VM, Gambhire VM, Gujar KN. Development and Evaluation of Sustained Release Pellets of Losartan Potassium by Extrusion - Spheronization Technique. World J Pharm Res. 2015;4(8):2913-23.

7. Shah RD, Kabadi M, Pope DG, Augsburger LL. Pysico-Mechanical Characterization of the ExtrusionSpheronization Process. Part II: Rheological Determinates for Successful Extrusion and Spheronization. 1995.

8. Saripella KK, Loka NC, Mallipeddi R, Rane AM, Neau SH. A Quality by Experimental Design Approach to Assess the Effect of Formulation and Process Variables on the Extrusion and Spheronization of Drug-Loaded Pellets Containing Polyplasdone® XL-10. AAPS PharmSciTech. 2016;17(2):368-79.

9. Kleinebudde P. The Crystallite-Gel-Model for Microcrystalline Cellulose in Wet-Granulation, Extrusion, and Spheronization. Pharm Res 14, 804-809 (1997).

10. Tho I, Kleinebudde P, Sande SA. Extrusion/Spheronization of Pectin-Based Formulations. I. Screening of Important Factors. AAPS PharmSciTech. 2001;2(4):1-2.

11. Tho I, Kleinebudde P, Sande SA. Extrusion/Spheronization of Pectin-Based Formulations. II. Effect of Additive Concentration in the Granulation Liquid. AAPS PharmSciTech. 2001;2(4):63-72.

12. Nattawut C, Peter KE, Satit P. Use of Chitosan-Alginate as Alternative Pelletization Aid to Microcrystalline Cellulose in Extrusion/Spheronization. Wiley Intersci. 2012;101(7):2271-80.

13. Santos H, Veiga F, Pina M, Podczeck F, Sousa J. Physical Properties of Chitosan Pellets Produced by Extrusion-Spheronisation: Influence of Formulation Variables. Int J Pharm. 2002;246(1-2):153-69.

14. Krueger C, Thommes M. Multiple Batch Manufacturing of Theophylline Pellets Using the WetExtrusion/Spheronization Process With K-Carrageenan as Pelletisation Aid. Pharm Dev Technol. 2013;18(1):225-35.

15. Sriamornsak P, Nunthanid J, Luangtana-anan M, Weerapol Y, Puttipipatkhachorn S. Alginate-Based Pellets Prepared by Extrusion/Spheronization: Effect of the Amount and Type of Sodium Alginate and Calcium Salts. Eur J Pharm Biopharm. 2008;69(1):274-84.

16. Sriamornsak P, Nunthanid J, Luangtana-anan M, Puttipipatkhachorn S. Alginate-Based Pellets Prepared by Extrusion/Spheronization: A Preliminary Study on the Effect of Additive in Granulating Liquid. Eur J Pharm Biopharm. 2007;67(1):227-35.

17. Afrasiabi GH, Dolatabadi R, Akhgari A, Abbaspour MR, Sadeghi F. Evaluation of Ethylcellulose and its Pseudolatex (Surelease) in Preparation of Matrix Pellets of Theophylline using Extrusion-Spheronization. Iran J Basic Med Sci. 2017;20(1):9-16.

18. Sadeghi F, Hijazi H, Garekani HA. Production of of Ibuprofen Pellets Containing High Amount of Rate Retarding Eudragit RL using PEG400 and Investigation of their Physicomechanical Properties. Iran J Basic Med Sci. 2011;14(4):383-90.

19. Abbaspour MR, Sadeghi F, Garekani HA. Preparation and Characterization of Ibuprofen Pellets Based on Eudragit RS PO and RL PO or Their Combination. Int J Pharm. 2005;303(1-2):88-94.

20. Hirjau M, Nicoara AC, Hirjau V, Lupuleasa D. Pelletization Techniques Used in Pharmaceutical Fields. Pract Farm [Internet]. 2011;4(3-4):206-11.

21. Rehana BA, Ganesh NS, vineeth C. A Study on Different Pellet Formation Techniques and Evaluation Parameter- a Review. Int J Curr Pharm Res. 2019;11(2). 
22. Iyer RM, Augsburger LL, Pope DG, Shah RD. Extrusion/Spheronization - Effect of Moisture Content and Spheronization Time on Pellet Characteristics. Pharm Dev Technol. 1996;1(4):325-31.

23. Amidon S, Brown JE, Dave VS. Colon-Targeted Oral Drug Delivery Systems: Design Trends and Approaches. AAPS PharmSciTech. 2015.

24. Muley S, Nandgude T, Poddar S. Extrusion-Spheronization a Promising Pelletization Technique: In-Depth Review. Asian J Pharm Sci [Internet]. 2016;11(6):684-99.

25. Bhairy SR, Habade BM,Gupta SK, Ghodke VR, Girkar YK, Kuchekar SK. Pellets And Pelletization As Multiparticulate Drug Delivery Systems (MPDDS): A Conventional And Novel Approach. Int J Institutional Pharm Life Sci. 2015;5(June):411-28.

26. Kammili L, Senthil V and Rathi V. Pelletization Technology : A Quick Review. Int J Pharm Sci ersearch. 2011;2(6):1337-55.

27. Srinivasarao k, Jyothimai KSL, Rao NR. Pellets And Pelletization Techniques: A Review. Int J Res Pharm Chem. 2017;7(2):141-7.

28. Puri V. Formulation and Evaluation of Immediate Release Pellets of Escitalopram oxalate. Int J Adv Pharm Sci. 2016;1(04):31-92.

29. Rao SK, Mishra VV, Nayak M. Pelletization technology in pharmaceutical formulation. Int J Adv Pharm Sci. 2019;1(January):0-10.

30. Kumar V, Mishra SK, Lather A, Singh R. Multiple Unit Dosage Form -Pellet and Pelletization Techniques: an Overview. Int J Res Ayurveda Pharm [Internet]. 2011;2(21):121-5. Available from: www.ijrap.net

31. Supriya P, Rajni B, Rana AC. Pelletization Techniques: a Literature Review. Int Res J Pharm. 2012;3(3):437.

32. Swarbrick J. Encyclopedia of Pharmaceutical Technology. Encyclopedia of Pharmaceutical Technology. 2013. 2651-2663.

33. Meenakshi B, Harsha S. Multiple Unit Particulate System : Pelletization Techniques : An Overview. Int J Pharm Erud. 2012;2(2):28-39.

34. Sirisha VRK, Suresh K, Vijayasree K, Devanna N, Murthy PN. Recent Advances in Pelletization Techniques - A Review. Int J Pharm Sci Rev Res. 2014;27(1):217-23.

35. Yadav N, Verma A. Pharmaceutical Pellets: A Versatile Carrier for Oral Controlled Delivery of Drugs. Indian J Pharm Educ Res. 2016;50(3):S146-60.

36. Deb R, Ahmed AB. Pellets and Pelletization Techniques: a Critical Review. Int Res J Pharm. 2016;4(4):905.

37. Bhaskaran S, Lakshmi PK. Extrusion Spheronization -A Review. Int J PharmTech Res. 2010;2(4):2429-33.

38. Rahman Md, Harwansh RK, Biswas R, Mirza MA. Hot Melt Extrusion and Freeze Pelletization: Better Alternative for Drugs Having Stability Problem Due to Presence of Water. Int J Pharm Sci Res [Internet]. 2010;1(11):22-31.

39. Vaphare AM, Banerjee SK, Gadhave MV, Gaikwad DD. Pelletization Techniques : A Review. Asian J Pharm Res Dev. 2014;2(3):103-14.

40. Ramu S, Ramakrishna G, Balaji M, Kondala K, Haranadh S. Multiple Unit Drug Delivery System: Pelletization Techniques. Am J Adv Drug Deliv. 2013;1(1):11-21.

41. Wan LSC, Heng PWS, Liew C V. Spheronization conditions on spheroid shape and size. Int J Pharm. 1993; 42. Eriksson M, Nyström C, Alderborn G. The Use of Air Permeametry for the Assessment of External Surface Area and Sphericity of Pelletized Granules. Int J Pharm. 1993;99(2-3):197-207.

43. Chopra R, Newton JM, Alderborn G, Podczeck F. Preparation of Pellets Of Different Shape and Their Characterization. Pharm Dev Technol. 2001;6(4):495-503.

44. Bathool A, Vishakante GD, Khan MS, Gupta VK. Pelletization As key Tool For Oral Drug Delivery: A Review. J Phamacy Res. 2011;4(10):3282-6.

45. Kandukuri JM, Allenki V, Eaga CM, Keshetty V, Jannu KK. Pelletization Techniques for Oral Drug Delivery. Int J Pharm Sci Drug Res [Internet]. 2009;1(2):63-70.

46. Tarkase KN, Garge SP,Bondre AB. Formulation And Evaluation Of Controlled Release Pellets of Metoprolol Succinate by Extrusion -Spheronization Method. Int J Drug Res Technol. 2012;2(5):407-10.

47. Gupta AM, Shivhare UD, Suruse PB. Different Aspects of Pellets Formulation and their Evaluation. Int J Phytopharm Res. 2015;4(6):331-6. 


\section{www.ijppr.humanjournals.com}

48. Aher U, Shelke T, Patel E. Recently used technologies in Pellet Formulation - A Review. PharmaTutor [Internet]. 2017;5(7):22-30.

49. Chakravarthy KK, Mohammad Y, Shaik S, Pisipati SVV. "Formulation and Evaluation of Enteric Coated Pellets of Omeprazole” Int. J. Drug Dev. \& Res., October-December 2012, 4(4):257-264.

50. Dudhamal SS, Kawtikwar PS, Nagoba SN. Formulation and Evaluation of Dispersible Pellets of Lagenaria Siceraria. Asian J Pharm Res Dev. 2018;6(4):81-5.

51. Anusha K, Babu M, Babu P. Formulation of Sustained Release Pellets of Quetiapine Fumarate by Fluidized Bed Coating Process. Int J Pharm Sci Invent [Internet]. 2013;2(12):20-33.

52. Singh G, Pai RS, Kusum Devi V. Optimization of Pellets Containing Solid Dispersion Prepared by Extrusion/Spheronization using Central Composite Design and Desirability Function. J Young Pharm. 2012;4(3):146-56.

53. Singh SK, Singh S, Seth NR, Ushir Y V., Patel R, Singh A. Design, Development and Evaluation of Domperidone Pellets. Int J PharmTech Res. 2009;1(3):885-91.

54. Mezreb N, Charrueau C, Boy P, Allain P, Chaumeil JC. Production of Carbopol 974P and Carbopol 971P pellets by extrusion spheronization. Optimization of the processing Parameters and water content. Drug. Dev. Ind. Pharm., 2004; 30: 481-90.

55. Hogan J. Pharma-the science of dosage form design. New York: Churchill Livingstone; 2001, pp. 441-448. 56. Ragnarsson G, Sandberg A, Johansson MO, Sjogren J. Development of a new controlled release metoprolol product. Drug DevInd Pharm 1987; 13: 1495-1509.

57. Bornhoft M, Thomames M, Kleinibudde P. Preliminary assessment of carrageenan as excipient for extrusion/ spheronization. Eur. J. Pharm. Biopharm., 2005; 59:127-31. 
www.ijppr.humanjournals.com

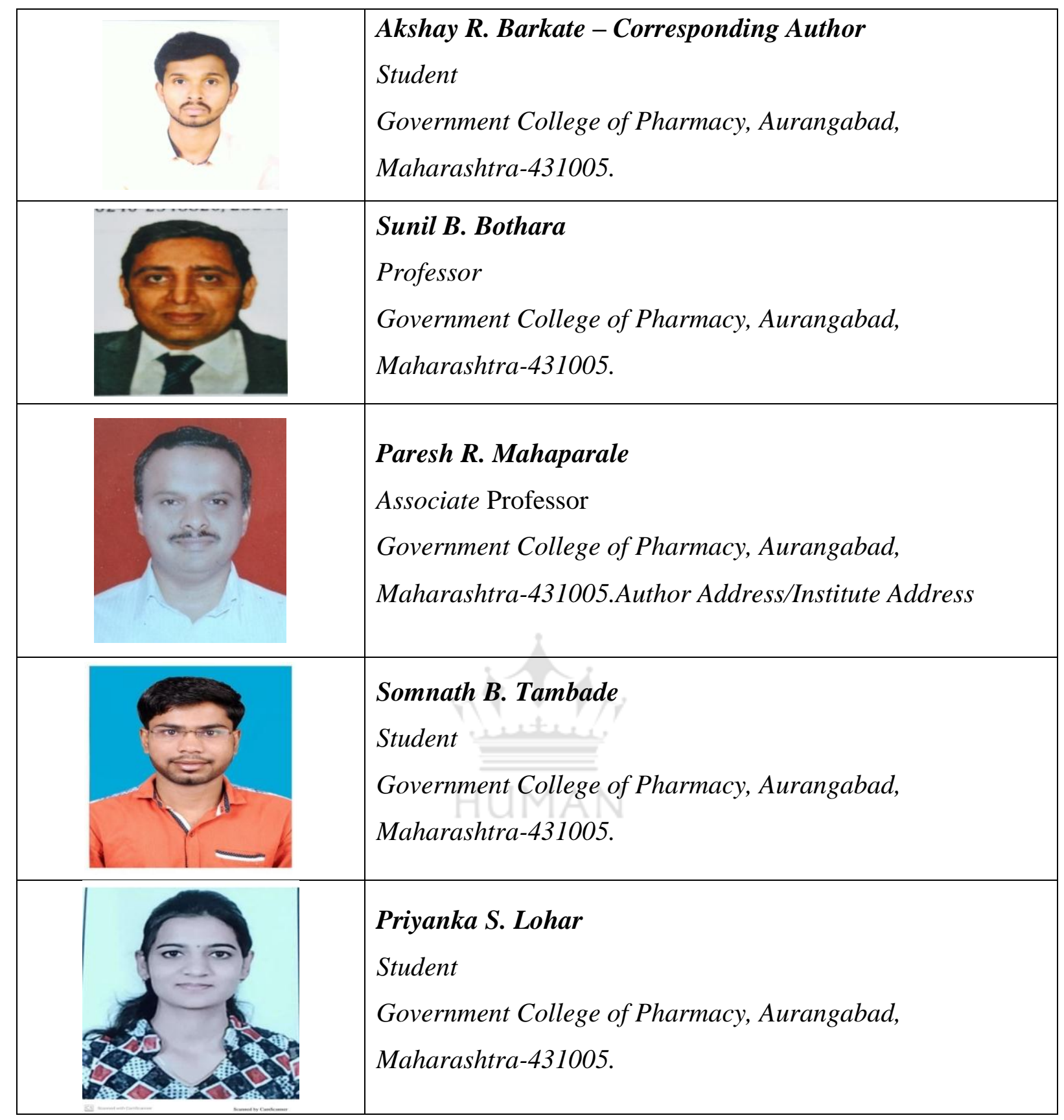

